\title{
Antibody Activity Against Mycobacterium leprae Antigen 7 During the First Year of DDS Treatment in Lepromatous (BL-LL) Leprosy
}

\author{
REIDAR MELSOM,* BEN NAAFS, MORTEN HARBOE AND OTTO \\ CLOSS
}

Armauer Hansen Research Institute (AHRI) and All-Africa Leprosy and Rehabilitation Training Centre (ALERT), Addis Ababa, Ethiopia, and University of Oslo, Institute for Experimental Medical Research, Ullevaal Hospital, Oslo 1, Norway

\begin{abstract}
A specific radioimmunoassay was developed for demonstration and quantitation of antibodies against Mycobacterium leprae antigen 7 which cross-react extensively with a similar antigen in many species of mycobacteria, including BCG-antigen-60.

The antibody activity against $M$. leprae antigen 7 showed only a slight tendency to decrease in 15 patients with lepromatous leprosy during their first year of treatment with dapsone associated with marked clinical improvement.
\end{abstract}

\section{Introduction}

Sera from patients with lepromatous leprosy contain strong antibodies against various mycobacterial antigens. The stimulus for their formation is probably antigens released from Mycobacterium leprae in vivo both during the subclinical stage and during the period with overt clinical disease. Prior stimulation by cross-reacting antigens originating from environmental mycobacteria may also be of importance for the intensity and the specificity of the antibody response. By double-diffusion tests in gel against a culture filtrate of Mycobacterium tuberculosis, Rees et al. (1965) found a gradual but steady fall in the amount of precipitating antibodies in lepromatous patients during dapsone (DDS) treatment.

Harboe et al. (1977a) have developed a specific radioimmunoassay for demonstration and quantitation of antibodies against BCG-antigen-60, a prominent antigenic component of BCG bacilli which cross-reacts with similar components in many mycobacterial species including $M$. leprae and $M$. tuberculosis. In a lepromatous serum pool there was anti-BCG-60 activity with

Received for publication 8 September 1977.

* Requests for reprints should be addressed to: Dr R. Melsom, Institute for Experimental Medical Research, Ullevaal Hospital, Oslo 1, Norway. 
a titre of $10^{5}$, whereas the titre in a tuberculoid serum pool was $10^{4}$. In tests of individual lepromatous sera, a striking variation in antibody content was observed. It has not yet been established to what extent variation in antibody content is related to particular clinical features. In tuberculoid leprosy, the median antibody content was distinctly lower than in lepromatous leprosy. Again there was a wide variation in antibody content in individual sera, and 5 out of 20 sera from patients with tuberculoid leprosy had a higher anti-BCG60 antibody content than the median value of the lepromatous group (Harboe et al., 1977b).

The purpose of the present investigation was:

(1) To develop a radioimmunoassay for antibodies against the corresponding antigen of $M$. leprae called $M$. leprae antigen 7 (Harboe et al., 1977c)

(2) To initiate a long term study of anti-M. leprae 7 antibody activity during DDS treatment of patients with lepromatous leprosy.

\section{Materials and Methods}

\section{PATIENT SERA}

Fifteen patients attending the Addis Ababa Leprosy Hospital were selected for the study. The patients were classified clinically and histologically according to the extended Ridley-Jopling scale (Ridley and Jopling, 1966; Ridley and Waters, 1969; Myrvang et al., 1973), 5 patients having LL, 5 patients having LI and 5 patients having BL leprosy. One patient (No. 11), included in Fig. 5, had a dual mycobacterial infection, BB/BL leprosy and tuberculosis. All the patients started treatment with DDS at the point of inclusion into the study, except one (patient No.13) with a disease history of 10 years. He had been treated with DDS for 2 years and then had no treatment for 8 years before inclusion into the study. The first bacteriological index was determined and the first serum sample was obtained at the beginning of the study. The median observation period was 12 months, with a range of 10 to 16 months.

Treatment consisted of DDS in a dose of $100 \mathrm{mg}$ daily, except in patient No. 1, a 13-year-old boy, who received $50 \mathrm{mg}$ DDS daily. The patients were seen regularly and evaluated by clinical criteria for regression of nodules, decrease of infiltration in the skin, nerve conduction velocity and bacteriological index.

\section{IMMUNOLOGICAL TECHNIQUES}

\section{Preparation and labelling of $\mathrm{M}$. leprae antigen 7}

The methods used were based on previous experience with purification and labelling of BCG-antigen-60 (Harboe et al., 1977a).

$M$. leprae was provided by IMMLEP as freeze-dried bacilli (the $\mathrm{A} / 10$ preparation) purified from liver tissue of an infected armadillo by Draper's procedure (Draper, 1976). M. leprae (60 mg dry weight) was suspended in $10 \mathrm{ml} 0.1 \mathrm{M}$ phosphate buffer $\mathrm{pH} 7.4$ and sonified on ice for $20 \mathrm{~min}$ with the 
Branson B-12 sonifier at $80 \mathrm{~W}$ effect (Branson Sonic Power Co., Danbury, Conn., U.S.A.). After centrifugation for $15 \mathrm{~min}$ at $20,000 \mathrm{~g}$ at $4^{\circ} \mathrm{C}$, the supernatant fluid was collected and served as unlabelled, crude $M$. leprae antigen. An aliquot of this preparation was labelled with ${ }^{125}$ I by electrolytic iodination as described previously (Harboe et al., 1977a). Free iodide and noncovalently bound iodide were removed by extensive dialysis against phosphatebuffered saline at $4^{\circ} \mathrm{C}$, and the iodinated preparation was diluted in immunoassay buffer and stored at $-25^{\circ} \mathrm{C}$ until used.

\section{Radioimmunoassay (RIA).}

The procedure previously described for assay of antibodies against BCGantigen-60 (Harboe et al., 1977a,b) was used. The technique is based on the separation of antibody-bound labelled antigen from free antigen by the use of protein A containing staphylococci which serve as a solid phase and have a marked capacity to bind IgG antibodies (Jonsson and Kronvall, 1974). Briefly, each tube contained $100 \mu \mathrm{l}$ of the appropriate serum dilution and $100 \mu \mathrm{l}$ of labelled $M$. leprae antigen 7 providing around 20,000 counts $/ 400 \mathrm{~s}$. The mixtures were incubated for $30 \mathrm{~min}$ at room temperature before addition of $2 \mathrm{ml} 1 \%$ formalinized staphylococci of the Cowan I strain (NCTC 85308). All dilutions of unlabelled (cold) and labelled proteins and of sera were made in immunoassay buffer of the following composition: phosphate-buffered saline of $\mathrm{pH} 7.4$ with $0.03 \mathrm{M} \mathrm{NaN}_{3}, 0.001 \mathrm{M}$ EDTA, and $0.2 \%$ human serum albumin (Reinst, Behringwerke, Marburg-Lahn, Germany). After the reagents had been mixed, the tubes were spun at $1500 \mathrm{~g}$ for $20 \mathrm{~min}$, the supernatant was carefully sucked off and the radioactivity determined in the bacterial pellet. All values are given as mean values of double tests and in experiments where this is appropriate expressed as radioactivity bound to staphylococci in per cent of maximum binding activity by a reference serum containing strong anti- $M$. leprae antigen 7 activity. To establish maximum binding activity, this serum pool was tested in dilutions $1: 10,1: 20,1: 40$ and 1:80. All these dilutions showed the same binding activity indicating antibody excess.

\section{TECHNICAL PROCEDURES}

The following procedures have been described previously: crossed immunoelectrophoresis (CIE) with intermediate gel (Axelsen et al., 1973; Harboe et al., 1976); radioautography (Harboe et al., 1977a); gel filtration (Harboe et al., 1977a); immunization procedures and antisera (Harboe et al., 1977c).

\section{Results}

DEVELOPMENT OF THE ASSAY FOR ANTIBODIES AGAINST M. LEPRAE ANTIGEN 7

Among the constituents of a BCG sonicate, antigen 60 has a particular affinity for iodine during electrolytic iodination. When crude preparations of BCG-antigen-60 with several contaminating antigens were iodinated, selective labelling occurred and the product could therefore be used for a specific assay 


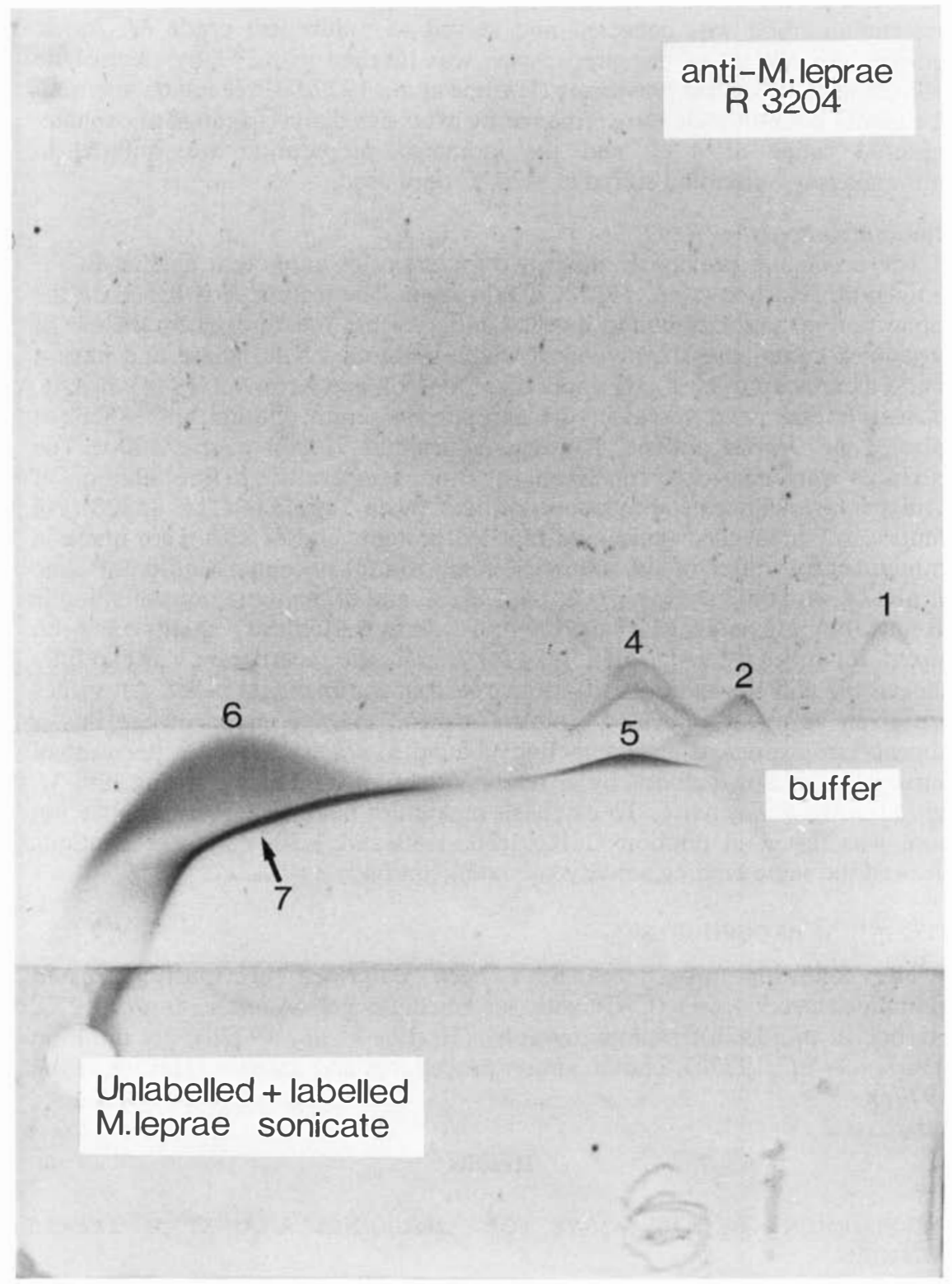

Fig. 1. Crossed immunoelectrophoresis of $M$. leprae sonicate mixed with ${ }^{125}$ I-labelled $M$. leprae sonicate. The left frame shows the plate after protein staining, the right frame after 


\section{anti-M.leprae R 3204}

\section{buffer}

\section{Unlabelled + labelled M. leprae sonicate}

radioautography. The bulk of the radioactivity was localized in a single precipitin line corresponding to antigen 7 . Weak radioactivity also occurred in component No. 2. 
of anti-BCG-60 antibodies (Harboe et al., 1977a). To examine whether the cross-reacting $M$. leprae antigen 7 has the same property, the A/10 M. leprae sonicate was iodinated in the same way.

Figure 1 shows crossed immunoelectrophoresis of a mixture of crude $\boldsymbol{M}$. leprae sonicate and ${ }^{125}$ I-labelled $M$. leprae sonicate using anti-M. leprae in the top gel. The left frame shows the pattern obtained by staining with Coomassie Brilliant Blue in which 6 distinct components are visible. They were numbered according to the previously published nomenclature for $M$. leprae antigens (Harboe et al., 1977c). Antigen 7 gives a very characteristic curved precipitin line. The right frame shows radioautography of the same plate. Intense staining of the film is seen corresponding to antigen 7. The film was exposed to the plate for 28 days to obtain a heavy exposure and thus a sensitive method to detect other labelled components. Nearer to the anode, another component is weakly labelled. Its form and position correspond to the precipitin line of $M$. leprae antigen 2.

When this labelled preparation was filtered through Sephadex G200, the bulk of the radioactivity appeared in a sharp peak corresponding to the void volume. These fractions were pooled, concentrated and tested by agarose gel electrophoresis. After electrophoresis, the gel was cut into segments and the radioactivity determined in each segment. Figure 2 shows the results obtained with the labelled crude $M$. leprae sonicate [Fig. 2(a)] and with the concentrated void volume material after gel filtration on Sephadex G200 [Fig. 2(b)]. It is seen that the greater part of the radioactivity occurred in segments 1 to 10 , i.e. in the most cathodic area and corresponding to the electrophoretic distribution of antigen 7. A distinct more anodic peak was obtained after electrophoresis of the crude labelled sonicate, but this fraction was smaller in the void volume material. In the latter instance, more than $95 \%$ of the radioactivity was localized in segments 1 to 12 , that is corresponding to the major part of $\boldsymbol{M}$. leprae antigen 7. The tendency to labelling of other components varied somewhat when different total sonicates of $\boldsymbol{M}$. leprae were used. Experiments are in progress to develop procedures for partial purification of $M$. leprae antigen 7 providing preparations in good yield and consistent monospecific assays after labelling.

- Figure 3 illustrates the results of experiments to evaluate the specificity of the radioimmunoassay. It shows that in dilution 1:10 and 1:100, a polyvalent anti- $M$. leprae antiserum did not react with more radioactive material in this labelled preparation than polyvalent anti-BCG immunoglobulin or monospecific anti-BCG-60 antiserum. This shows that the radioimmunoassay detects antibody activity against $M$. leprae antigen 7 , which has been shown previously to cross-react with BCG-antigen-60. Polyvalent antisera did not bind more radioactivity than monospecific anti-BCG-60. These findings were taken as proof that the radioimmunoassay was monospecific for detection of antibodies against $M$. leprae antigen 7 .

Figure 4 shows the results of tests for antibody activity in rabbit anti- $M$. leprae antisera and in various pools made from human sera. It may be seen that the lepromatous serum pool contains potent antibodies against $M$. leprae antigen 7. The pool of sera from patients with tuberculoid leprosy also had strong antibody activity, but with a distinctly lower titre. To compare the 


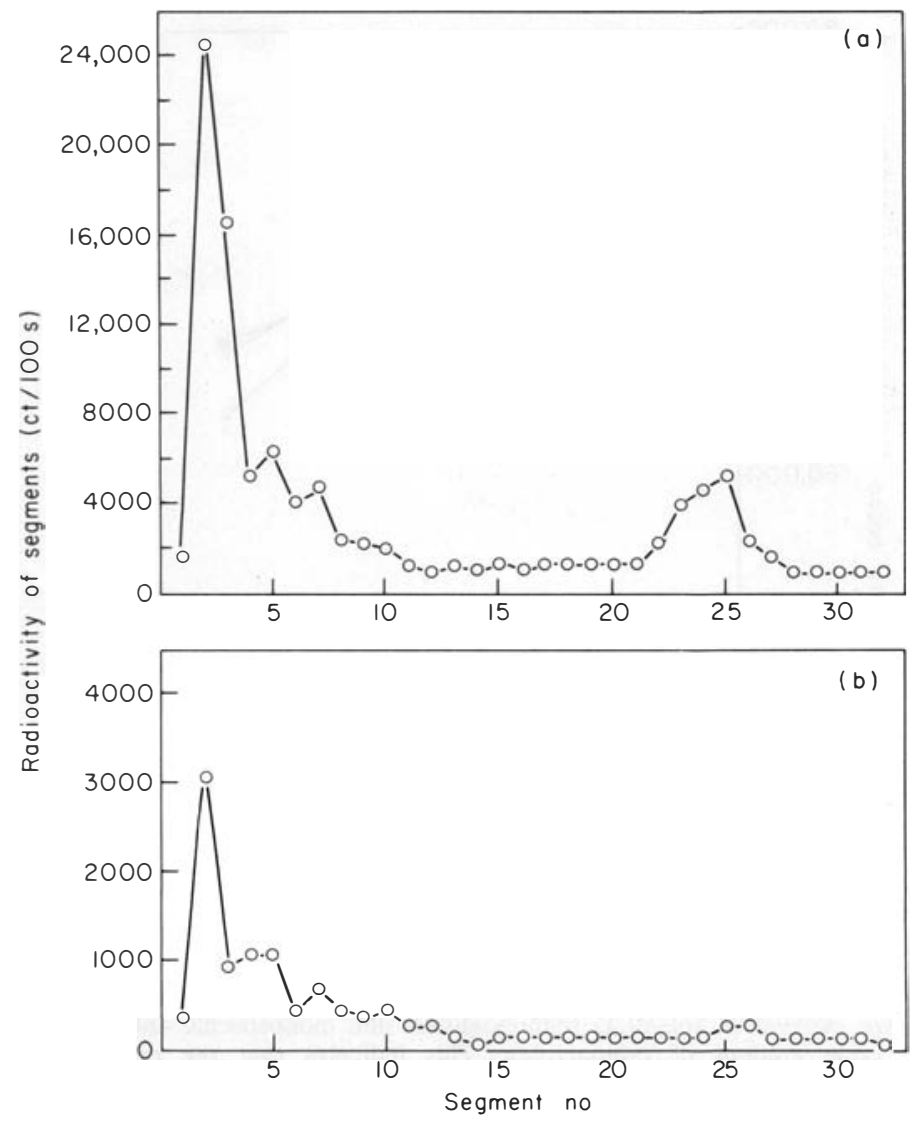

Fig. 2. Agarose gel electrophoresis of labelled M. Leprae sonicate (a) and concentrated void volume material after gel filtration through Sephadex G 200 (b). The bulk of the radioactivity occurred in segments 1 to 10 corresponding to the electrophoretic distribution of antigen 7. A small, but distinct peak occurred in later segments. After electrophoresis of the void volume material, the second peak was smaller amounting to less than $5 \%$ of the total radioactivity.

antibody content of different serum samples taken from the same individual, several principles may be used. We decided to test a single dilution made simultaneously from all serum samples obtained from a given patient and to test them against the same labelled antigen preparation. A dilution of 1:10,000 was selected to provide an assay sensitive for variation in antibody content. Many lepromatous sera will give maximum binding activity at dilution 1:1000 and at this dilution the system is rather insensitive to changes in antibody concentration particularly with regard to the strongest reacting sera.

Figure 5 shows the results of tests of 9 different patients whose curves were typical of all the patients observed.

Patients No. 8 and 10 showed a continuous and slight decrease in antibody 


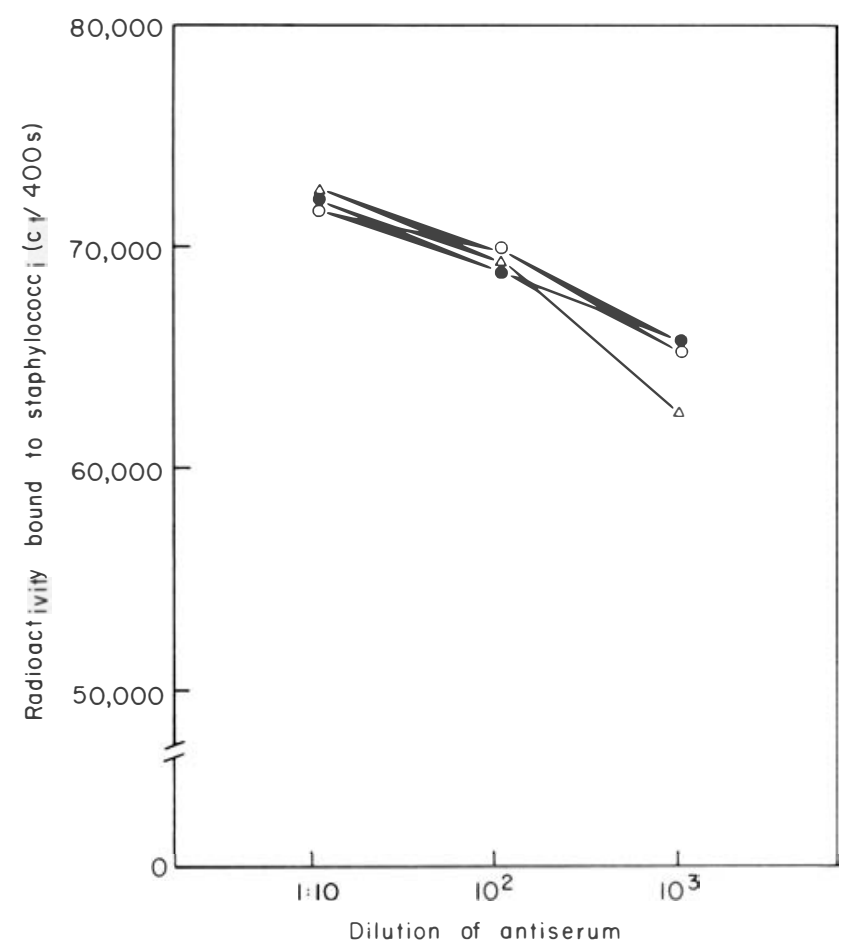

Fig. 3. Radioimmunoassay with ${ }^{123} I$-labelled $M$. leprae sonicate. At dilution 1:10 and 1:100, anti-M. leprae, polyvalent anti-BCG immunogloblin and monospecific anti-BCG-60 antibody bound the same amount of radioactivity. This indicates that the radioimmunoassay is monospecific for antibodies against $\boldsymbol{M}$. leprae antigen 7 which cross-reacts with BCG-antigen60. $(\triangle-\triangle)$ Anti-M. leprae; (O-O) anti-BCG; $(\bullet-\bullet)$ anti-BCG-60.

activity during the observation period. Patient No. 6 showed a marked fluctuation in antibody activity and patients No. 7, 16 and 17 showed patterns with less fluctuation. Taken as a whole, the findings showed that there is a tendency to slowly decreasing concentration of antibodies against anti- $M$. leprae antigen 7 during the first year of DDS treatment in lepromatous leprosy. Careful clinical observations with demonstration of resolving nodules, decreasing infiltration in affected skin areas, decreasing bacteriological index, and marked improvement in nerve conduction velocity demonstrated a clinical effect of the DDS treatment as expected in patients with DDS sensitive bacilli. The form of the curves did not show any consistent pattern related to clinical improvement or to development of reactions which were observed in 11 of the patients. Nine of them experienced slight to moderate erythema nodosum leprosum (ENL), and 2 had severe ENL.

Patient No. 11, included in Fig. 5, is the only one in whom antibody activity increased slowly and steadily throughout the observation period. He was entered into the study in May 1975 with a diagnosis of BB/BL leprosy and 


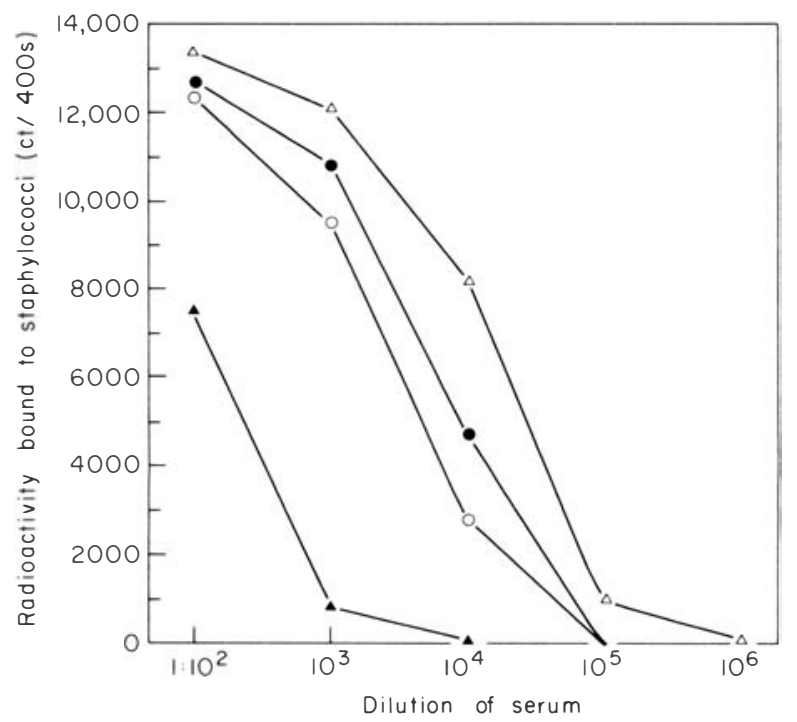

Fig. 4. Radioimmunoassay for antibodies against $M$. leprae antigen 7 in 4 serum pools.

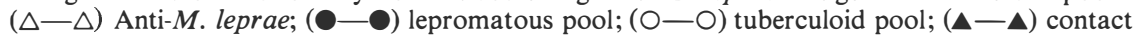
pool.

developed a typical reversal reaction. In August 1975 treatment with prednisolone had to be started and he was given $30 \mathrm{mg}$ daily for 1 week, $20 \mathrm{mg}$ daily for 2 weeks and $10 \mathrm{mg}$ daily for 7 months. In October 1975 he developed clinical and X-ray features of active pulmonary tuberculosis. Since he suffered from a dual mycobacterial infection he was excluded from the calculation of the decrease in antibody activity in Table 1 . The demonstration of a steady increase in antibody concentration in this patient should be related to the previous observation that sera from patients with active pulmonary tuberculosis often contain strong anti-BCG-60 antibodies (Harboe et al., 1977b).

\section{Discussion}

Recent studies with CIE have provided new information on the antigenic structure of mycobacteria. In several mycobacterial species, e.g. $M$. tuberculosis, $M$. smegmatis and $M$. lepraemurium, more than 40 distinct antigenic components have been detected (Closs et al., 1975; Kronvall et al., 1975; Janicki et al., 1976). Immune reactions in mycobacterial disorders should therefore be studied in terms of reactions against defined antigenic components of the mycobacteria. This requirement is difficult to fulfil in studies of cell-mediated immune reactions since this would require studies using highly purified antigenic components of the mycobacteria.

For characterization of antibody specificity in mycobacterial infection, crossed immunoelectrophoresis with intermediate gel containing patient serum is a particularly valuable technique (Axelsen et al., 1974; Closs and Kronvall, 


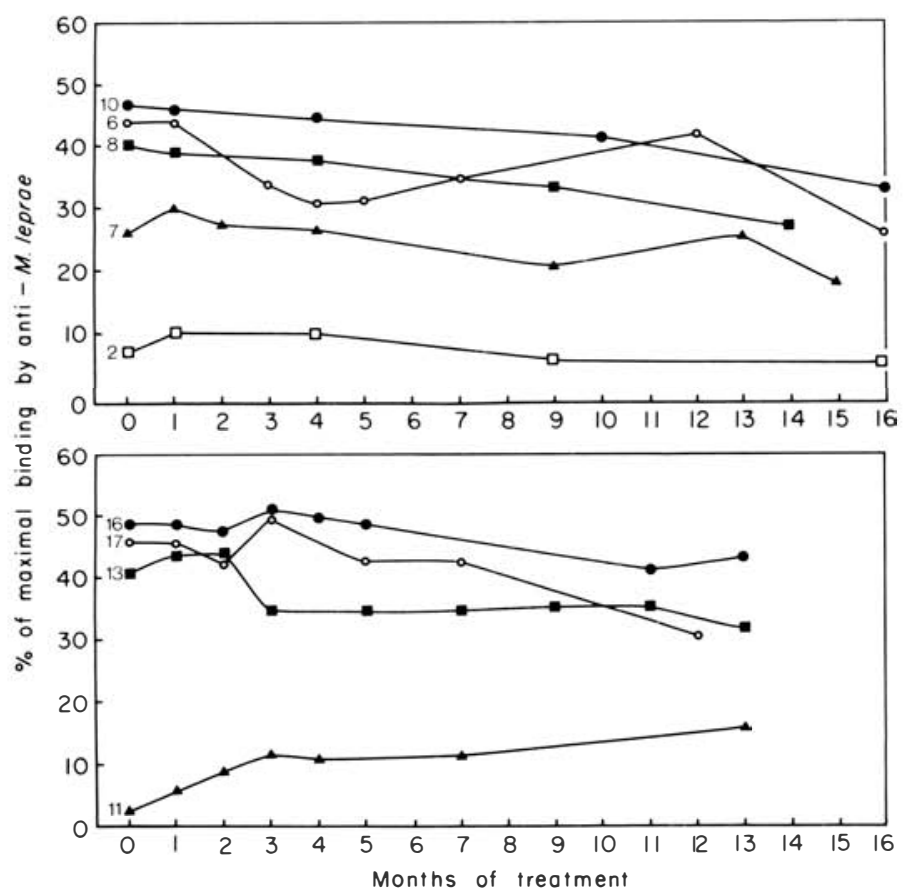

Fig. 5. Radioimmunoassay for antibodies against $\boldsymbol{M}$. leprae antigen 7 in serial serum samples obtained from 9 patients during the first year of DDS treatment for lepromatous leprosy. The ordinate shows antibody activity expressed as percent of maximal binding by a polyvalent antiM. leprae antibody.

1975, Kronvall et al., 1975; Harboe et al., 1977c). For quantitative and sensitive studies of antibody formation against defined antigenic components, radioimmunoassays may be used. Monospecific test systems can be established provided that an antigenic preparation is available in which only one component is labelled. In this case the test will only detect antibody activity against this component even though other antigen antibody reactions may take place simultaneously in the tube, but against unlabelled components.

Harboe et al. have developed a specific radioimmunoassay for antibodies against BCG-antigen-60 and have used the assay to study antibody formation against this antigen in rabbits during experimental immunization (Harboe $e t$ al., 1977a), and in leprosy and in various types of control sera (Harboe et al., $1977 b$ ). In the present paper, we describe a similar test for demonstration and quantitation of antibodies against the cross-reacting antigen 7 of M. leprae. To the best of our knowledge this is the first quantitative test for antibodies against a defined protein component of $M$. leprae.

Figure 5 and Table 1 show that there is a slight decrease in antibody activity against this antigen during the first year of DDS treatment in lepromatous leprosy. On the whole, the startling observation is that anti-M. leprae antigen 7 activity remains strong in patients with lepromatous leprosy during the first 
TABLE 1

Antibody activity against M. leprae antigen 7 in 15 patients with lepromatous leprosy before and after 10 to 16 months treatment with $D D S$

\begin{tabular}{cccc}
\hline Patient No. & \multicolumn{2}{c}{$\begin{array}{c}\text { Antibody activity } \\
\text { At the start } \\
\text { of the study }\end{array}$} & $\begin{array}{c}\text { At the end } \\
\text { of the study }\end{array}$ \\
\hline 1 & 25 & 24 & -1 \\
2 & 7 & 6 & -1 \\
3 & 31 & 32 & +1 \\
6 & 44 & 28 & -16 \\
7 & 26 & 19 & -7 \\
8 & 40 & 30 & -10 \\
9 & 41 & 35 & -6 \\
10 & 47 & 35 & -12 \\
12 & 43 & 37 & -6 \\
13 & 41 & 32 & -9 \\
14 & 45 & 42 & -3 \\
16 & 49 & 44 & -5 \\
17 & 46 & 32 & -14 \\
18 & 44 & 32 & -12 \\
20 & 49 & 27 & -22 \\
& & Median value & -7.0 \\
\hline
\end{tabular}

year of DDS treatment even when they show marked clinical improvement. Our observations regarding a single, although widely cross-reacting antigen of $M$. leprae are very similar to those of Rees et al. (1965). By double-diffusion tests in gel against a culture filtrate of $M$. tuberculosis, they found a gradual but steady fall in the amount of precipitating antibodies in lepromatous leprosy during DDS treatment.

Bjorvatn et al. (unpublished observations) used serial serum samples from individual patients with lepromatous leprosy in the top gel of CIE against an $M$. leprae sonicate. The precipitate pattern, i.e. the antibody specificity, varied from patient to patient but it was remarkably stable in each patient during the first year of DDS treatment.

Currently available $M$. leprae sonicates contain fewer antigenic components than similarly prepared sonicates from cultivable mycobacteria. These components in $M$. leprae are characterized by extensive cross-reactions with other species of mycobacteria (Harboe et al., 1977c). M. leprae is characterized by a long generation time. Several years of bacterial growth are therefore required after the initial infection to produce the clinical features observed in our patients. The immune system of these patients has thus been exposed to antigens released from live, dying or dead leprosy bacilli during several years. This prolonged exposure is probably a very potent stimulus for the immune system. In addition, these patients are also exposed to antigens from other environmental mycobacteria. The latter stimulus may induce antibody formation in normal individuals (Harboe et al., 1977b) and may also be important to sustain the antibody production in patients treated for 
mycobacterial disease. Acid-fast bacilli are destroyed very slowly in humans and in experimental animals, even during effective treatment of mycobacterial infections. Taken together, these features indicate that it may take several years before anti-mycobacterial antibodies disappear during DDS treatment of leprosy. $M$. leprae antigen 7 cross-reacts with a similar antigen in many other species of mycobacteria. Additional information concerning the stimulus for antibody formation in leprosy should be obtained by comparing the behaviour of antibodies against widely cross-reacting antigens with antibodies reacting with antigenic determinants specific for $M$. leprae in long term studies.

\section{Acknowledgements}

This work was supported by grants from Anders Jahre's Fund for the Promotion of Science and the Norwegian Research Council for Science and the Humanities. The work was also supported by the World Health Organization through its Immunology of Leprosy (IMMLEP) programme.

Anti-BCG Immunoglobulin was kindly provided by Dakopatts A/S, Copenhagen, Denmark.

We thank R. J. W. Rees and P. Draper, National Institute for Medical Research, London, for purified $M$. leprae, J. M. H. Pearson for clinical assistance and histological classification of the patients, and Else-Marie Skalle for excellent technical assistance.

\section{References}

Axelsen, N. H., Krøll, J. and Weeke, B. (Eds) (1973). A Manual of Quantitative Immunoelectrophoresis. Methods and Applications. Scand J. Immunol. 2 (Suppl. 1), $169 \mathrm{pp}$.

Axelsen, N. H., Harboe, M., Closs, O. and Godal, T. (1974). BCG antibody profiles in tuberculoid and lepromatous leprosy. Infect. Immun. 9, 952.

Closs, O., Harboe, M. and Wassum, A. M. (1975). Cross-reactions between mycobacteria. I. Crossed immunoelectrophoresis of soluble antigens of Mycobacterium lepraemurium and comparison with BCG. Scand. J. Immunol. 4, (Suppl. 2), 173.

Closs, O. and Kronvall, G. (1975). Experimental murine leprosy: IX. Antibodies against Mycobacterium lepraemurium in $\mathrm{C} 3 \mathrm{H}$ and $\mathrm{C} 57 \mathrm{BL}$ mice with murine leprosy and in patients with lepromatous leprosy. Scand.J. Immunol. 4, 735.

Draper, P. (1976). Cell walls of Mycobacterium leprae. Int.J. Lepr. 44, 95.

Harboe, M., Closs, O. and Deverill, J. (1976). Production of monospecific antisera against antigenic components of Mycobacterium bovis (BCG) Scand.J. Immunol. 5, 861.

Harboe, M., Closs, O., Svindahl, K. and Deverill, J. (1977a). Production and assay of antibodies against one antigenic component of Mycobacterium bovis BCG. Infect. Immun. 16, 662.

Harboe, M., Closs, O., Bjorvatn, B. and Bjune, G. (1977b). Antibodies against BCG antigen 60 in mycobacterial inf ection. Brit. med.J. 2, 430.

Harboe, M., Closs, O., Bjorvatn, B., Kronvall, G. and Axelsen, N. H. (1977c). The antibody response in rabbits to immunization with Mycobacterium leprae. Infect. Immun. 18, 792.

Janicki, B. W., Wright, G. L., Jr., Good, R. C. and Chaparas, S. D. (1976). Comparison of antigens in sonic and pressure cell extracts of Mycobacterium tuberculosis. Infect. Immun. 13, 425.

Jonsson, S. and Kronvall, G. (1974). The use of protein-A containing Staphylococcus aureus as a solid phase anti-IgG reagent in radioimmunoassays as exemplified in the quantitation of $a$-fetoprotein in normal human adult serum. Eur. J. Immunol. 4, 29. 
Kronvall, G., Bjune, G., Stanford, J., Menzel, S. and Samuel, D. (1975). Mycobacterial antigens in antibody responses of leprosy patients. Int. J. Le pr. 43, 299.

Myrvang, B., Godal, T., Ridley, D. S., Frøland, S. S. and Song, Y. K. (1973). Immune responsiveness to Mycobacterium leprae and other mycobacterial antigens throughout the clinical and histopathological spectrum of leprosy. Clin. exp. Immunol. 14, 541.

Rees, R. J. W., Chatter jee, K. R., Pepys, J. and Tee, R. D. (1965). Some immunologic aspects of leprosy. Amer. Rev. resp. Dis. 92 (Suppl), 139.

Ridley, D. S. and Jopling, W. H. (1966). Classification of leprosy according to immunity. A fivegroup system. Int. J. Le pr. 34, 255.

Ridley, D. S. and Waters, M. F. R. (1969). Significance of variations within the lepromatous group. Lepr. Rev. 40, 143. 